\title{
Environmental Issues and Challenges of Chinese Abandoned Oil Pipelines
}

\author{
Hongtao Wang ${ }^{1}$, Fajie Yang ${ }^{2, *}$, and Rongguang $\mathrm{Li}^{2}$ \\ ${ }^{1}$ Department of pipeline protection, Pipeline Company of PetroChina, LangFang, HeBei Province, China \\ ${ }^{2}$ Division of security and environment, PetroChina Pipeline R\&D Center, LangFang, HeBei Province, China
}

\begin{abstract}
China energy pipeline industry commonly faced with aging and abandonment problem. The research on pipeline abandonment was still in preliminary state, because there are no pipeline abandonment standards and guidelines. The foreign developed countries formulated pipeline abandonment standards, advanced experience and technology of residual cleaning and the crossing section grouting. But it not totally suitable for china because of difference between china and foreign country, such as the pipeline residual has a very high paraffin and resin-asphaltenes content. It is very hard to remove. So china pipeline company faced with many environmental issues and challenges in the pipeline abandonment. Study on abandonment of pipeline was conducted by pipeline company of Petrochina from 2013. A case of Petrochina abandonment pipeline was introduced in the paper, and it showed good effect. Some experience and technology of chemical cleaning were formulated from previous study and several pipeline abandonment projects. The first China industry standard on abandoned pipeline is applying for by pipeline company of Petrochina. This standard will assist pipeline company make pipeline abandonment plan to ensure public safety and environment protection.
\end{abstract}

\section{Introduction}

The energy pipeline in China has been increasing for the past many decades. The all of energy pipeline in china exceeds ten thousand kilometres by now[1]. This pipeline infrastructure is fundamental to the efficient, safe and reliable delivery of crude oil and refinery oil from overseas to domestic markets, from oil fields to refinery factory or customers.

Among the investigated laws, regulations and standards promulgated in countries such as the United States, Canada and Australia, they all have requirements about pipeline abandonment, but their focus is on disposal of abandoned pipelines; namely, after pipeline abandonment, how to select effective disposal method that will neither damage environment nor pose threat to public security, and there is no uniform regulation for pipeline abandonment. Mostly, abandonment of pipeline abroad is decided by their own decision of the enterprises, which will be supervised and audited by special government organizations. For example, according to Code of Federal Regulations Chapter 15 Commerce and Trade 15B-Natural Gas Article 717f, the available supply of natural gas is depleted to the extent that the continuous service fails to be provided to ensure the present or future public convenience or necessity, permit such abandonment[2]. According to Explanation of Rules and Regulations of Abandonment of Gas Service Lines and Leakage Survey Procedures of Massachusetts of the United States, the pipeline operator can decide if a pipeline is to be abandoned based on its service life, location, status, material, construction method, pipeline leakage and maintenance record, condition of cathodic protection and other criteria that the operator chooses, but the requirement is only in principle[3].

In the oil and gas pipeline standard system abroad, pipeline abandonment is an important part of pipeline operation and maintenance, for instance, the Canadian standard CAN/CSA Z662-11, Oil and Gas Pipeline Systems; and the Australian standard AS 2885.3-2012 Pipeline-Gas and Liquid Petroleum Part 3: Operation and Maintenance. But in china, because of lacking abandoned pipeline standard and guidelines, if the pipeline is abandoned, the pipeline company will not maintain the pipeline any longer. Without maintenance the abandoned pipeline will rapidly corrosion. The subsidence leaked from the abandoned pipeline will contaminant the ground water, underground water and the soil. This will arise serious environmental issues.

Since the promulgation of Oil and Gas Pipeline Protection Law of the China in 2010, associated laws were newly modified or developed, including Environmental Protection Law of the People's Republic of China, Water protection Law of the People's Republic of China, and some guideline on soil Protection have been successively promulgated. China gets more focus on environmental issue of abandoned pipeline. The first China industry standard on abandoned pipeline is applied for in 2015, named technical specifications for

\footnotetext{
* Corresponding author: doodle115@sina.com
} 
the disposal of an abandoned oil and gas long distance pipeline. Meanwhile, the rapid advancement of urbanization promotes upgrading of pipelines in the areas where the pipelines pass, which adds more environmental sensitive areas and areas of highly potential consequences and enhances more pressure on safety and environmental protection for pipelines. Approximately 3000 kilometres oil pipelines of Petrochina in northeast of china reach the end of their useful lives, and will be abandoned. The residual in the pipeline is hard to remove because the residual is comprised of paraffin deposits, mechanical impurities and other particles from oil pipelines and tanks. Almost all of crude oils of china have high per cent of wax and resin-asphaltenes. This is different from that of others country. There is no experience available to use. So, there are many environmental issues and challenges in disposal of abandoned oil pipeline.

\section{Disposal of abandoned pipeline}

\subsection{Abandonment options}

There are two basic options that are considered when abandoned pipeline is disposed. They are abandonment in-place and pipeline removal. For the disposal of abandoned pipeline projects, it is expected that a combination of treatments will be used, based on site specific assessments. Most common issues are dealt with including the following aspect.

-Regulatory requirements

-Environmental considerations

-Land use

-Soil and groundwater contamination

-Ground subsidence

-Pipeline cleaning

-Erosion

-Water crossings

-Rail, road or utility crossings

-Post-abandonment responsibilities

-Cost of abandonment

In china, cathodic protection of pipeline is not continued and no other measures are taken to maintain the structural integrity of the abandoned pipeline. Normally, an important factor influencing to the choice between the options is present and future land use. But it is unlikely the only one of the two options will be employed for many large scale abandonment projects. In another word, a project will usually involve a combination of pipe removal and abandonment-in-place along the length of the pipeline. It is further found that the abandonment techniques presented are confined to those possible using currently available technology the usually used in U.S and Canada etc. while developments in pipeline removal and abandonment technologies were evaluated, no major improvements to the methods is made. However, with the increasing of abandoned pipeline, the better methods will likely be developed. The first China industry standard on abandoned pipeline named technical specifications for the disposal of an abandoned oil and gas long distance pipeline is applied for by pipeline company of Petrochina in 2015. The objective of the standard is to assist the maker in the development of pipeline abandonment plan to ensure that public safety and environment protection.

The decision to abandon in place or removal should be made on the basis of a comprehensive assessment. The land of following place may be better suited to pipeline abandonment in-place include, but are not limited to:

-Parks and natural areas

-Unstable or highly erodible surfaces

-Water crossing

-Flood irrigated fields

-Railway and road crosslings

-Extra depth burial of pipe (i.e. depth well in excess of one metre)

-Native prairie and native parkland

-Forest cut blocks

-Designated waterfowl and wildlife habitat;

-Areas exhibiting poor and/or limited access.

Situations suitable for removal:

-Pipe buried in less of one meter;

-Aboveground pipeline and facilities;

-Pipeline coating with hazardous material;

-Pipeline in area with prospective future development

The local government or Pipeline Company is responsible for the pipeline systems. When pipeline reaches the abandonment standard in china, the pipeline operator applies for abandonment demand and the National energy administration will organize a meeting to assess whether it should be abandoned or not. The abandonment plan should be disscussed in the meeting. It should be meet the need of both the local goverment and the other related management departments.

\subsection{Technology for pipeline abandonment}

Many technologies were firstly developed in the United states, Canada, Netherland, Russia etc. it includes the following technologies[4], but not limited to:

-Residual cleaning

-Grouting

-Plugging

-Removing

-Waste treatment

Cleaning the residuals in the pipeline is the first step to dispose the abandoned pipeline. After cleaning residual the pipeline will be abandoned in place or removed. Many countries have strict requirement for oil concentration of pipeline after cleaning internal residuals. Thailand, the concentration of oil and grease in the final flushed water should be below or equal to $15 \mathrm{ppm}$. Latvian, the residual concentration of hydrocarbons in water (VOC) allowed by local authorities was $30 \mathrm{mg} / \mathrm{l}$. Brazil, oil/wax content must be less than 20 ppm. China, oil/wax content should be less than $20 \mathrm{ppm}$ only for offshore pipeline, there is no regulation for onshore pipeline. Thus for many oil pipelines with heavy wax the combined cleaning method (i.e. pigs + chemical cleaning agent) is the best option. 
Preferably, whether in-place abandoned pipelines or removal pipelines should be cleaned free of solids or any waxy build up. The most critical determinant for ensuring pipeline cleanliness is effective pigging.

Complete pipeline collapse is not typically encountered in active pipeline, and is unlikely to result from a geohazard. If cathodic protection of an abandoned pipeline is not continued, the pipeline becomes pitted with corrosion, and it will eventually collapse. For small diameter pipeline (168 mm or less) collapse may have few consequences. However, collapse of large diameter pipelines can lead to subsidence, which in environmentally or geo-technically sensitive areas would require grouting. Furthermore, pipeline also need to be grouted to reduce flushing out probability of pipeline in water crosslings and water discharge points. There are many grouting materials that could be chosen according to the demand of grouting. The grouting material include, but not limited to cement, mortar, crushed stone, polymer foam etc.

\subsection{Chemical cleaning of abandoned pipeline}

\subsubsection{Effect of chemical cleaning}

Removing hazardous pipeline content from pipeline by chemical cleaning should be considered as a very early step of pipeline abandonment process. Chemical cleaning is very important step. It can instantly achieve of safe conditions for flame cutting and welding (no flammable vapors in the pipeline), improve safety and reduce time \& costs of dismantling work. Chemical cleaning can eliminate risk of environment pollution during dismantling and modification work. So the residual in the pipeline cannot pollute the surrounding environment any longer.

Studies have shown that significant quantities of contaminants may be left in abandoned pipelines as a result of poor cleaning operation. The following factors will influence the affection of cleaning operation.

-Pipeline configuration (e.g. bends and doglegs)

-Type and quantity of chemical cleaning agent

-Type of pig and proper pig use

-Diameter of pig

-Chemical cleaning procedure

In general, the pigging wastes are usually accepted by oilfield waste disposal company, oil refinery plant and waste water disposal company according to the result of the detailed chemical analysis.

\subsubsection{Assessment of pipeline's piggability}

If a pipeline company wants to clean an abandoned pipeline by chemical cleaning agent. It should firstly assess the pipeline's piggability. In another word, the pipeline must be piggable. Furthermore, the pipeline also can withhold pressure needed for the pigging process. Pipeline can be chemical cleaned by pig trains containing bathes of cleaning agent. Piggability of an abandoned pipeline is based on pipeline's following details:
-OD/ID, pipe type,

-Elevation profile,

-Detailed scheme - cross-section reductions, branches, elbow details, valve design, and any other important details.

\subsubsection{Procedure of chemical cleaning}

If an abandoned pipeline is piggable, chemical cleaning could be started. Usually, chemical cleaning procedure includes the following steps:

-Pipeline dividing to cleaning sections

-Local modifications,

-Installation of temporary pig traps,

-Calculation of needed contact time and volume of chemical cleaning agents,

-Composition of cleaning pig trains (number of pigs), volume and content of cleaning batches and pig train travel speed,

-Delivery of suitable pigs, chemical agents, pumps, air compressors, nitrogen units etc.

-Disposal of waste.

The whole cleaning procedure and waste disposal should be described in a detailed engineering study. Pipeline should be cleaned by pigging as well as possible prior to other pipeline abandoned disposal.

\subsubsection{Chemical cleaning agent}

Usually, there are two types of cleaning agents they could be selected. They are hydrophobic cleaning agents (oil soluble) and hydrophilic agents (water soluble)[5]. Oil soluble cleaning agents are mainly used to improve the efficiency of pipeline cleaning process to remove paraffins and dissolve hard paraffin deposits from internal pipeline wall. Water soluble cleaning agents can very efficiently remove rests of oil from internal pipeline surface. Choice of chemical agents are based on

-Composition of crude oil,

-Content and nature of deposits - paraffin, hard deposits, black powder,

-Pigging history.

Choice of suitable cleaning agents is very important for the job. It usually depends on the laboratory experiment.

\subsection{Pigging of abandoned pipeline}

Cleaning plan is made according to the detailed study of abandoned pipeline. How to clean an abandoned pipeline by cleaning agent is well illuminated by the figure1. Chemical cleaning operation is usually made by experienced field engineers and technicians. Pipeline abandoned in-place should be cleaned to meet all applicable guidelines and regulatory requirements.

Disposal of cleaning waste depends on local conditions and possibilities and also on chemical agent volume used. Oil soluble agents are typically 0.1 to $0.5 \%$ of pipeline volume. Oil products with a very high dissolving ability can be utilized in an oil refinery or simply pumped into another crude oil pipeline. Usually 
this has a cleaning effect in that pipeline as it helps to free existing paraffin debris. Water soluble agents including last water batches are typically 1 to $8 \%$ of pipeline volume. Water product can be utilized in a chemical refinery or disposed by waste water disposal company.

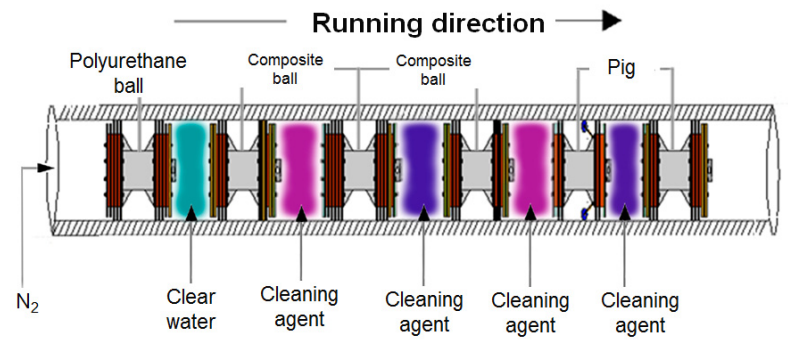

Figure 1 Chemical cleaning of abandoned pipeline

\section{Pipeline abandonment case of Petrochina}

Many pipelines in northeast pipe matrix of china face serious integrity problem. As people's concern about pipeline safety, environment protection and government's strict regulation, many old pipelines servicing more than 30 years will be abandoned. The length of pipeline needing to be abandoned reaches to approximately 3000 kilometres. Since 2013 many works have been done by the major china oil company such as PetroChina. There is no standards for oil and gas pipeline abandonment in China.

The target of this case is one kilometer pipe selected from abandoned pipeline about 300 kilometres. Thickness of the residual is about $15-20 \mathrm{~mm}$. It can be seen from a picture of the Figure 2. Firstly, the one kilometer pipe was divided from the abandoned pipeline. It was not pigged in the past, but integrity of the pipeline is good. It can hold with the pressure needed for the pigging proecess. The pipeline is respectively pigged by pathfinder ball, polyurethane pig, straight plate pig and paraffin crapper pig once time or more. Residual was collected and analysed. Suitable cleaning agent was selected according to the contents of residual. The residual is dominated by paraffin and resin-asphaltenes. The time of contact between cleaning agent and residual during long-distance cleaning is short. The cleaning can be conducted under normal temperature. Thus the cleaning agent used is mainly used for paraffin removal, and shall have features such as high cleaning speed, large saturation under normal temperature. A kind of water soluble cleaning agents is used to ensure very efficient removal rests of oil from internal pipeline surface. A detail cleaning plan was made according to the all of factors. After ten days cleaning of pig train, the effect of cleaned inner surface is showed in the $b$ picture of Figure 2.

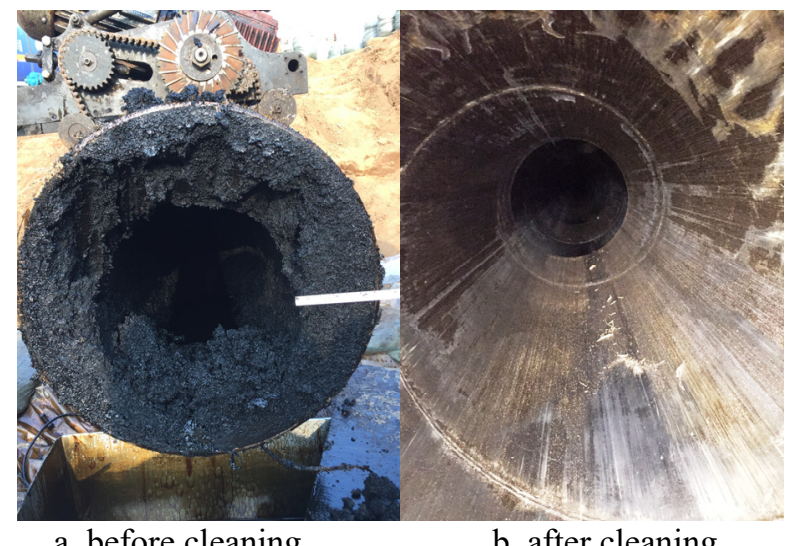
a. before cleaning
b. after cleaning
Figure 2 Effect of chemical cleaning

From the figure, it can be seen that good cleaning effect was obtained. The cleaned pipeline meets the requirements of pipeline company and local government. Because the pipeline is closed to the building of resident, it was abandoned in place. Many kinds of chemical cleaning agents (oil and water soluble) suitable for residuals with high paraffin and resin-asphaltene contents were developed by the pipeline abandonment case of Petrochina.

\section{References}

1. T. Wang, X. Wang, L. Z. Rong, L.N. Xue, Z. B. Gao, T. W. Wang, J. Oil \& Gas stor. and trans., 36, 11 (2017)

2. Z. H. Chen, International Vintage Pipeline Abandonment Seminar 2015, Langfang, June 18-22, (2015)

3. Y. W. Kang, International Vintage Pipeline Abandonment Seminar 2015, Langfang, June 36-40 (2015)

4. S. C. Liu, Y. C. Liu, X. X. Zhang, W. Zhang, W. P. Ma, Total Cor. Contro 29, 11(2015)

5. I. N. Poraiko, V. K. Galyuk, oil industry, 9, 11(1979) 